This item was submitted to Loughborough's Research Repository by the author.

Items in Figshare are protected by copyright, with all rights reserved, unless otherwise indicated.

\title{
A link between plant stress and hydrodynamics? Indications from a freshwater macrophyte
}

PLEASE CITE THE PUBLISHED VERSION

https://doi.org/10.1029/2021WR029618

PUBLISHER

Wiley, AGU

VERSION

VoR (Version of Record)

PUBLISHER STATEMENT

This is an Open Access Article. It is published by Wiley under the Creative Commons Attribution 4.0 Unported Licence (CC BY). Full details of this licence are available at: http://creativecommons.org/licenses/by/4.0/

\section{LICENCE}

CC BY 4.0

\section{REPOSITORY RECORD}

Vettori, Davide, S Niewerth, J Aberle, and Stephen Rice. 2021. "A Link Between Plant Stress and Hydrodynamics? Indications from a Freshwater Macrophyte". Loughborough University.

https://hdl.handle.net/2134/16794301.v1. 


\section{Water Resources Research}

\section{RESEARCH ARTICLE \\ 10.1029/2021WR029618}

Key Points:

- The hydrodynamics of freshwater macrophytes can be affected by the conditions in the field and storage procedure used prior to experiments

- This impact is quantified as up to $30 \%$ of the drag coefficient, similar to the impact associated with using different macrophyte species

- Higher levels of plant stress are associated with lower drag forces

Correspondence to:

D. Vettori,

davide.vettori@polito.it

Citation:

Vettori, D., Niewerth, S., Aberle, J., \& Rice, S. P. (2021). A link between plant stress and hydrodynamics? Indications from a freshwater macrophyte. Water Resources Research, 57, e2021WR029618. https://doi. org/10.1029/2021WR029618

Received 12 JAN 2021 Accepted 17 AUG 2021
(C) 2021. The Authors.

This is an open access article under the terms of the Creative Commons Attribution License, which permits use, distribution and reproduction in any medium, provided the original work is properly cited.

\section{A Link Between Plant Stress and Hydrodynamics? Indications From a Freshwater Macrophyte}

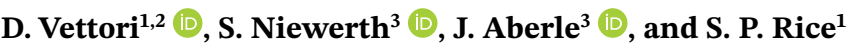 \\ ${ }^{1}$ Geography and Environment, School of Social Sciences and Humanities, Loughborough University, Loughborough, \\ UK, ${ }^{2}$ Now at Department of Environment, Land and Infrastructure Engineering, Politecnico di Torino, Torino, Italy, \\ ${ }^{3}$ Division of Hydraulic Engineering and River Morphology, Leichtweiß Institute for Hydraulic Engineering and Water \\ Resources, Technische Universität Braunschweig, Braunschweig, Germany
}

\begin{abstract}
Live plants are increasingly used in hydraulic laboratories to investigate flow-vegetation interactions. In such experiments, they are often exposed to stressful handling and storage that can cause strong physiological responses and modifications in plant biomechanics. Little is known about the potential effect of these impacts on the performance of plants during hydraulic experiments. In this multidisciplinary study with a freshwater macrophyte (Potamogeton natans) we assess whether the duration and the conditions in which plants are stored in a laboratory prior to testing can impact plant stress, biomechanics and hydrodynamics, and quantify this impact. Plant stress was evaluated using chlorophyll fluorescence analysis (and the maximum quantum yield of photosystem II as specific indicator). Plant hydrodynamics were assessed using the drag coefficient calculated from drag force measurements at two flow scenarios. The results show that different plant handling/storage procedures can have a significant impact on plant hydrodynamics even within a short time frame, with a variation of the mean drag coefficient of approximately $30 \%$ across groups, which is comparable to the variation found across different species of freshwater macrophytes in previous studies. Plants with the highest level of stress were also characterized by the lowest drag coefficient across the groups considered, suggesting a potential link between plant stress and hydrodynamics.
\end{abstract}

Plain Language Summary Aquatic plants are used in laboratory experiments designed to understand how they affect water velocity, sediment movement and the distribution of substances in the water. Plants are moved from the field or nursery to the laboratory, where the light conditions are often insufficient for photosynthesis and the water quality can be poor; this can lead to deterioration in plant health and cause plants to physically change. Here we use a common aquatic plant to investigate how such changes can affect the force associated with the water flow that pulls the plant downstream (drag force). To measure plant health, we used an indicator of photosynthesis efficiency, to measure plant rigidity we conducted bending tests on plant stems, and to measure the drag force on the plant we carried out tests in a channel equipped with a force sensor. The results show that the drag force experienced by plants depends on how, and for how long, they have been stored and that stressed plants are better at avoiding some of the drag force. This has implications for scientists who use live plants in laboratory experiments, indicating that storage and handling prior to experiments can have a significant effect on the results.

\section{Introduction}

Vegetation plays multiple roles in the ecological and physical processes of aquatic ecosystems, and many studies have investigated the interplay of vegetation and hydraulics in coastal and riverine vegetation settings. For example, coastal vegetation has been extensively studied to assess the role of saltmarshes (e.g., Lara et al., 2016; Möller et al., 2014) and seagrass (e.g., Infantes et al., 2012; James et al., 2019; Lei \& Nepf, 2019) in coastal protection through wave attenuation and reduction of sediment transport. Riparian vegetation has been investigated to understand its impact on river morphodynamics (e.g., Bertoldi et al., 2015; Tal \& Paola, 2010) and how it contributes to flow resistance during flooding events (e.g., Aberle \& Järvelä, 2013; Armanini et al., 2005; Västilä \& Järvelä, 2014). Studies have been conducted to assess the hydrodynamics of freshwater macrophytes (e.g., Siniscalchi \& Nikora, 2012) and how their nutrient uptake is influenced by local flow conditions (Cornacchia et al., 2019). The interactions between vegetation and flowing water 
and the role of vegetation in sediment transport processes across spatial scales have been reviewed by Nikora (2010), Folkard (2011), Nepf (2012), Gurnell (2014), and Larsen (2019) among others.

Various recent investigations of flow-vegetation interactions have made use of live plants in laboratory settings. This approach is advantageous because it ensures some degree of experimental control within the facility while ensuring that the biomechanical complexity of real plants is properly represented (Thomas et al., 2014). In hydraulic engineering practice, the benefits of using live vegetation rather than artificial replicates has been recently pointed out by Aberle and Järvelä (2013) for floodplain vegetation and Vettori and Nikora (2020) for submerged flexible vegetation. Aberle and Järvelä (2013) report that modeling plants as rigid cylinders makes it difficult to parameterize the drag force, and consequently the flow resistance, correctly. Vettori and Nikora (2020) provide evidence that using artificial replicates of seaweeds causes a substantial underestimation of the drag force even though replicates were designed following an appropriate similarity theory. As long as the potential of numerical works is constrained by (a) insufficient data on vegetation biomechanics and (b) limited knowledge of biological and physical processes with which vegetation interacts with flowing water and sediments, we expect that future progress in this research area will be heavily based upon laboratory experiments conducted with live vegetation.

Laboratory experiments are commonly designed around physical processes, with limited consideration of conditions such as temperature, light availability and water quality, even though these can substantially affect plant physiology. Vettori and Rice (2020) found that in hydraulic facilities across Europe live plants are often exposed to suboptimal laboratory conditions. Most commonly, laboratories are characterized by levels of light irradiance that are inadequate for plant photosynthesis and water quality is not managed. Even short-term exposure to such conditions is associated with significant increases in plant stress and modifications of the biomechanical properties of freshwater macrophytes (Vettori \& Rice, 2020). Additionally, it is possible that plants experience a transient stress when moved from the field to the laboratory (i.e., when they are collected). Given the established relationships (e.g., through the Cauchy number) linking plant biomechanics to hydrodynamics (e.g., Nikora, 2010), such modifications have the potential to affect plant hydrodynamics, for example altering the drag force.

At first glance, the effect on the hydrodynamics of a single plant may seem to have limited relevance for practical applications. However, determining biased drag coefficients at the plant scale can result in inaccurate estimates of flow resistance at the reach scale. According to the classical definition, the drag force $F_{D}$ acting on a submerged plant is a function of the approach flow velocity, the plant characteristic area and the drag coefficient. Using a "static approach" (sensu Statzner et al., 2006) for defining flow velocity and plant area, the drag force $F_{D}$ exerted on a plant can be obtained as:

$$
F_{D}=\frac{1}{2} \rho C_{D} A_{w} U_{a}^{2}
$$

where $\rho$ is the water density, $C_{D}$ and $A_{w}$ are the drag coefficient and wetted surface area of the plant, and $U_{a}$ is the mean approach velocity (in front of the plant). Upscaling from a single plant to a reach scale, flow resistance can be characterized using the Darcy-Weisbach friction factor $(f)$. This factor can account for both flow resistance related to the bed material $\left(f_{b}\right)$ and that associated with the drag force exerted on vegetation $\left(f_{v}\right.$; e.g., Aberle \& Järvelä, 2013) by using the linear superimposition principle according to $f=f_{b}+f_{v}$ (e.g., Yen, 2002). The friction factor $f_{v}$ related to the presence of vegetation can be obtained from a spatially averaged drag force $\left\langle F_{D}\right\rangle$ per unit bed area, which inevitably depends on $C_{D}$ (Aberle \& Järvelä, 2013), that is:

$$
f_{v}=\frac{8\left\langle F_{D}\right\rangle}{\rho U_{m}{ }^{2}}
$$

where $U_{m}$ is the spatially averaged mean flow velocity.

The authors are not aware of any previous study in which the time and conditions of storage of plants prior to experiments and resultant plant hydrodynamics have been investigated in a systemic manner. This correlation, if confirmed, would have considerable implications in the study of vegetated flows because it would imply that the results of hydraulic experiments are, to some extent, dependent on the way in which plants are handled and stored. Therefore, the main objective of the present paper is to assess whether the storage of plants prior to hydraulic experiments is associated with physiological stress and changes in plant hydrodynamic performance. In particular, we aim to address three research questions: 


\begin{tabular}{|c|c|c|c|c|c|}
\hline Group & Water & $\begin{array}{l}\text { Temperature } \\
\left({ }^{\circ} \mathrm{C}\right)\end{array}$ & $\begin{array}{l}\text { Conductivity } \\
(\mu \mathrm{S} / \mathrm{cm})\end{array}$ & $\begin{array}{l}\text { Light irradiance (PAR) } \\
\qquad\left(\mu \mathrm{mol}_{\text {photon }} / \mathrm{m}^{2} / \mathrm{s}\right)\end{array}$ & $\begin{array}{l}\text { Exposure time } \\
\text { before tests }(d)\end{array}$ \\
\hline A & Pond and flume water & $19.7-23.1$ & $568-590$ & $34-37$ & 2 \\
\hline B & Flume water & $20.3-21.1$ & $368-413$ & $34-38$ & 7 \\
\hline $\mathrm{C}$ & Flume water & $19.6-21.7$ & $360-386$ & $0.3-3.1$ & 8 \\
\hline Site & Pond water & 30.1 & 1,000 & 1,000 & - \\
\hline
\end{tabular}

Note. Values for the collection site refer to the date and time of collection (June 5, 2019 at 17:00).

1. Can typical pre-experimental storage procedures induce plant stress?

2. Can plant hydrodynamic performance be affected by conditions at the collection site and storage procedure?

3. Is there a link between plant stress and hydrodynamics?

To address these questions, we conducted laboratory experiments with samples of Potamogeton natans, a freshwater macrophyte, exposed to different treatments so that a range of plant stress was achieved. Freshwater macrophytes were used because they are generally flexible and, consequently, are expected to have a strong biomechanical response to environmental stressors (Vettori \& Rice, 2020). For each plant, we measured: plant stress, morphological characteristics, flexural rigidity, and drag force, deflected height and vertical distribution of plant biomass at two different flows. It is worth noting that in the present work the term "stress" is used to describe the plant response to the laboratory conditions, not the conditions themselves, which are referred to as "stressors" in the following text.

\section{Materials and Methods}

\subsection{Experimental Design and Procedure}

A total of 24 samples of $P$. natans were collected from a pond $\left(52.309^{\circ} \mathrm{N}, 10.606^{\circ} \mathrm{E}\right)$ created by the river Schunter and located near Braunschweig, Germany. At the time of collection, Photosynthetic Active Radiation (PAR) was approximately $1,000 \mu \mathrm{mol}_{\text {photon }} / \mathrm{m}^{2} / \mathrm{s}$, water temperature was $30.1^{\circ} \mathrm{C}$, and water conductivity was $1,000 \mu \mathrm{S} / \mathrm{cm}$ (Table 1 ). Immediately after collection plants were brought to the hydraulic laboratory of the Leichtweiß-Institute for Hydraulic Engineering and Water Resources (LWI), Technische Universität Braunschweig. The plants were randomly allocated to three groups and each group to one of three mesocosms (eight plants per mesocosm) characterized by different conditions (Table 1). Each mesocosm consisted of a 30-50 l container filled with water and aerated using an air pump.

The conditions in the mesocosms were designed based on the findings of our previous work (Vettori \& Rice, 2020) which indicated that plant stress is negatively correlated with the flexural rigidity of plant stems. Among the most common abiotic stressors encountered in laboratory facilities, short-term exposure to low light irradiance and immersion in tap water were identified as the most stressful for three freshwater macrophyte species. In the current study, Group A was used as a reference group and the plants were tested within $48 \mathrm{~h}$ of collection so that the effects of laboratory storage conditions were minimized and transient stress limited. Group B was designed to expose plants to the stress induced by water used in the flumes for experiments (i.e., from the LWI-hydraulic laboratory water circuit)—characterized by the presence of artificial seeding materials used in acoustic and optical flow velocimetry and potentially lacking important nutrients for plant growth. Group $\mathrm{C}$ was designed to expose plants to a combination of potential stressors: water used in the flumes and a light irradiance level insufficient for photosynthesis. Plants in Groups B and C were used after 7 and 8 days, respectively, to guarantee their response to the laboratory conditions.

In more detail, in Group A, a mix of pond water and water used in the LWI-hydraulic laboratory water circuit was employed (approximate ratio was 75:25) and a fluorescent lighting unit was installed to increase the level of PAR compared to the standard light conditions of the laboratory (Table 1). In Groups B and C 
only water from the LWI-hydraulic laboratory water circuit was used; in Group B a dedicated fluorescent lighting unit was installed similar to Group A, while in Group C plants were exposed to the standard light conditions of the laboratory - a mix of natural light and light from standard ceiling lights. The day-night light cycle for Groups A and B was set so that it matched the natural light cycle experienced by Group C, hence plants were exposed to $15 \mathrm{~h}$ of light per day. In all groups water temperature was not controlled and, thus, varied within a small range-note that the maximum temperature for Group A is higher than that of the remaining groups because at the time of collection the water temperature in the pond was $30^{\circ} \mathrm{C}$. In each mesocosm water temperature and conductivity and PAR at the water surface were measured daily.

On the day of testing, all plants within a group were removed from the mesocosm and a standard experimental procedure was followed for each plant: plant stress was measured using a chlorophyll fluorometer (procedure described in Section 2.2); plant hydrodynamic performance was characterized in an open channel flume by measuring the drag force (described in Section 2.3); and plant morphological characteristics and flexural rigidity of stems were determined (described in Section 2.4).

\subsection{Chlorophyll Fluorescence as a Proxy of Plant Stress}

Chlorophyll fluorescence analysis is a standard technique used in plant physiology to monitor plant health status. It exploits the fluorescence signal emitted by chlorophyll pigments when they are struck by light and, thus, provides information on the photosynthetic phenomena occurring within the photosystem II (PSII) (e.g., Baker, 2008; Murchie \& Lawson, 2013). As reported in several comprehensive reviews (Baker, 2008; Baker \& Rosenqvist, 2004; Maxwell \& Johnson, 2000; Murchie \& Lawson, 2013) this technique is very sensitive to plant stress associated with inhibition of the photosynthetic apparatus (i.e., photoinhibition) and allows non-intrusive and non-destructive measurements. Chlorophyll fluorescence analysis has been previously used to monitor plant stress of freshwater macrophytes exposed to abiotic stressors such as extreme light irradiance and contaminants of various kinds (e.g., Hussner et al., 2010; Marwood et al., 2001).

For our study we made use of the maximum quantum yield $\left(F_{V} / F_{M}\right)$ of PSII as an indicator of plant stress. This parameter was calculated as the ratio of variable fluorescence $\left(F_{V}\right)$ to maximum fluorescence $\left(F_{M}\right)$ using measurements from dark-adapted plants before dawn following standard practice reported in Baker (2008) and Murchie and Lawson (2013). The maximum quantum yield was selected because it is a robust indicator of plant stress causing damage to the PSII and its value is commonly reported to be close to 0.83 for healthy, unstressed plants, regardless of the species (e.g., Murchie \& Lawson, 2013). In more detail, predawn $F_{V} / F_{M}$ displays a substantial decrease when plants are exposed to severe and long-term suboptimal conditions that induce important photoinhibition, while it is less sensitive to mild stresses (Murchie \& Lawson, 2013). Reduction of $F_{V} / F_{M}$ is usually associated with a lower photosynthetic efficiency, this may be effective at low ambient light levels but does not compromise photosynthesis when light levels are high-in such cases photosynthetic efficiency is considerably lower than the observed $F_{V} / F_{M}$ (Baker, 2008). For the purposes of this study, it is important to bear in mind that the higher the value of $F_{V} / F_{M}$ the healthier is the plant. Even though typical values of $F_{V} / F_{M}$ for $P$. natans have not been reported in the literature, we expect $F_{V} / F_{M}$ to range between 0.7 and 0.83 for healthy unstressed plants based on previous publications (e.g., Hanelt et al., 2006; Marwood et al., 2001; Vettori \& Rice, 2020) with freshwater macrophytes.

We measured $F_{V} / F_{M}$ using a Classic Fluorometer (Aquation Pty Ltd, Umina Beach, Australia). During the measurements the light irradiance level was approximately $0.2 \mu \mathrm{mol}_{\text {photon }} / \mathrm{m}^{2} / \mathrm{s}$ so that photosynthetic activity would not be triggered (Baker \& Rosenqvist, 2004). Measurements of $F_{V} / F_{M}$ were taken from at least three healthy leaves on each plant. All measurements were used for comparing the plant stress across the three groups (see Section 3.1), while the average value of $F_{V} / F_{M}$ across all tested leaves within a plant was used for assessing the potential correlation between $F_{V} / F_{M}$ and the drag coefficient of individual plants (see Section 3.4).

\subsection{Hydrodynamic Experiments}

Hydrodynamic experiments were performed after plant stress was evaluated with the chlorophyll fluorometer. Experiments were conducted in a $32 \mathrm{~m}$ long and 0.6 wide tilting open channel flume in the LWI-hydraulic laboratory. In the central part of the flume, between 5 and $23 \mathrm{~m}$ from the inlet, a rubber mat with $3 \mathrm{~mm}$ 


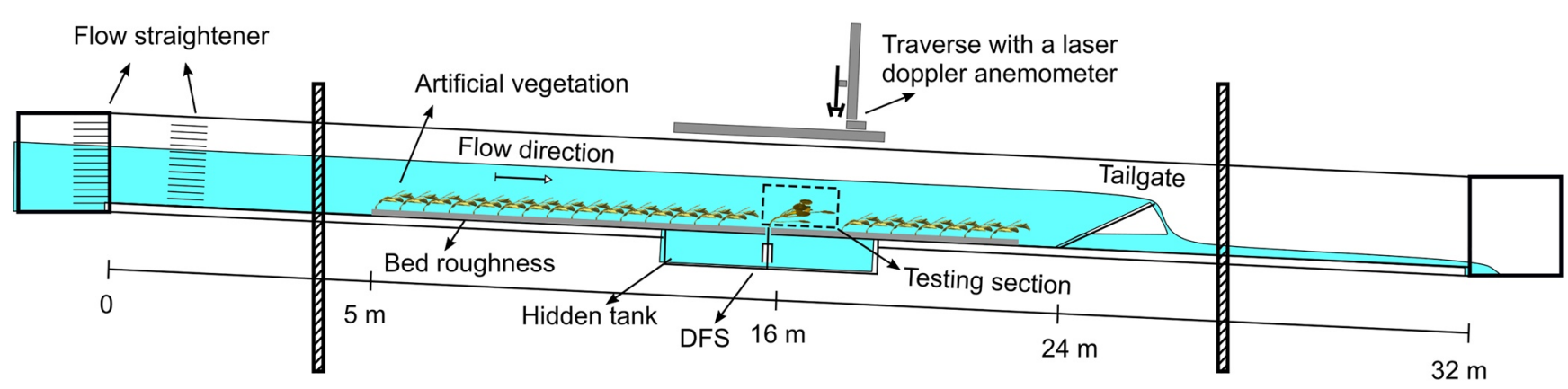

Figure 1. Schematics of the open-cannel facility used for hydrodynamic experiments and relevant instrumentation.

high pyramidal-shaped roughness elements was fixed to the flume bed and a canopy of artificial vegetation was installed. The canopy consisted of identical flexible foliated elements $15 \mathrm{~cm}$ high that were arranged following a staggered pattern with a distance between two adjacent elements of $0.2 \mathrm{~m}$ (plant arrangement 20S, Jalonen et al., 2013; Schoneboom, 2011).

At a distance of $16 \mathrm{~m}$ from the inlet, the artificial vegetation elements were removed to create a $0.6 \mathrm{~m}$ long testing section (Figure 1) in which specimens of $P$. natans could be located for experiments. This setup allowed investigation of a single specimen within a patch setting typical of freshwater macrophytes in the field (e.g., Biggs et al., 2018; Cornacchia et al., 2018). Each plant was tested at two flow scenarios with hydraulic conditions described in Table 2 . The scenario with low mean flow velocity was tested first, followed by the scenario with high mean flow velocity. All experiments were performed at quasi-steady uniform flow conditions, which were achieved by adjusting bed slope, flow discharge and the height of a tailgate located $25 \mathrm{~m}$ downstream of the flume inlet (Figure 1). The water depth and flow discharge were measured using 12 piezometers located along the flume and an inductive flow meter, respectively. Even though the length of plants tested was larger than the water depth used in the experiments-plant length was between 0.3 and $0.45 \mathrm{~m}$, plants were always fully submerged because of their high flexibility and the flow-induced forces.

After the hydraulic conditions were set, the plant to be tested was fitted onto a Drag Force Sensor (DFS) located under the bottom of the flume at the center of the cross-section and at the upstream edge of the testing section (Figure 1). The DFS is the same measuring system used in the studies of Schoneboom (2011), Siniscalchi et al. (2012), Jalonen et al. (2013), and Västilä and Järvelä (2014) and it was described comprehensively by Schoneboom et al. (2008). It is based on two Wheatstone bridges in full configuration each comprised of two strain gauges; strain data are converted into drag force by using a calibration force and the geometrical properties of the sensor. On the side of the flume glass wall, a digital camera was mounted and used to record plant reconfiguration during experiments. Because the plant was fixed to the DFS at the upstream edge of the testing section, plant reconfiguration could be monitored without interference from the artificial vegetation elements (Figure 1). Each plant was tested for 5 min, during which time the drag force was measured at a frequency of $1,613 \mathrm{~Hz}$ and the digital camera recorded at $30 \mathrm{fps}$.

Table 2

Hydraulic Conditions Used in the Experiments

\begin{tabular}{lcccccccc}
\hline Scenario & $\begin{array}{c}\text { Flow } \\
\text { rate } \\
\left(\mathrm{m}^{3} / \mathrm{s}\right)\end{array}$ & $\begin{array}{c}\text { Water } \\
\text { depth } \\
(\mathrm{m})\end{array}$ & $\begin{array}{c}\text { Bed } \\
\text { slope } \\
(\%)\end{array}$ & $\begin{array}{c}\text { Water } \\
\text { surface } \\
\text { slope }(\%)\end{array}$ & $\begin{array}{c}\text { Cross-sectional } \\
\text { averaged } \\
\text { velocity }(\mathrm{m} / \mathrm{s})\end{array}$ & $\begin{array}{c}\text { Mean } \\
\text { approach } \\
\text { velocity }(\mathrm{m} / \mathrm{s})\end{array}$ & $\begin{array}{c}\text { Reynolds } \\
\text { number } \\
(-)\end{array}$ & $\begin{array}{c}\text { Plant } \\
\text { Reynolds } \\
\text { number }(-)\end{array}$ \\
\hline Low & 0.018 & 0.30 & 0.05 & 0.04 & 0.10 & 0.106 & $3 \times 10^{4}$ & $2.4 \pm 0.2 \times 10^{4}$ \\
High & 0.064 & 0.26 & 0.36 & 0.33 & 0.41 & 0.393 & $1.06 \times 10^{5}$ & $9.0 \pm 0.9 \times 10^{4}$ \\
\hline
\end{tabular}

Note. The cross-sectional averaged velocity is estimated from the flow rate, while the mean approach velocity is calculated as the double-averaged velocity in front of the plant (from LDA measurements). The Reynolds number is calculated using the cross-sectional averaged velocity and the water depth, while the plant Reynolds number (mean \pm standard deviation) is calculated using the mean approach velocity and the square root of the plant wetted surface area. 


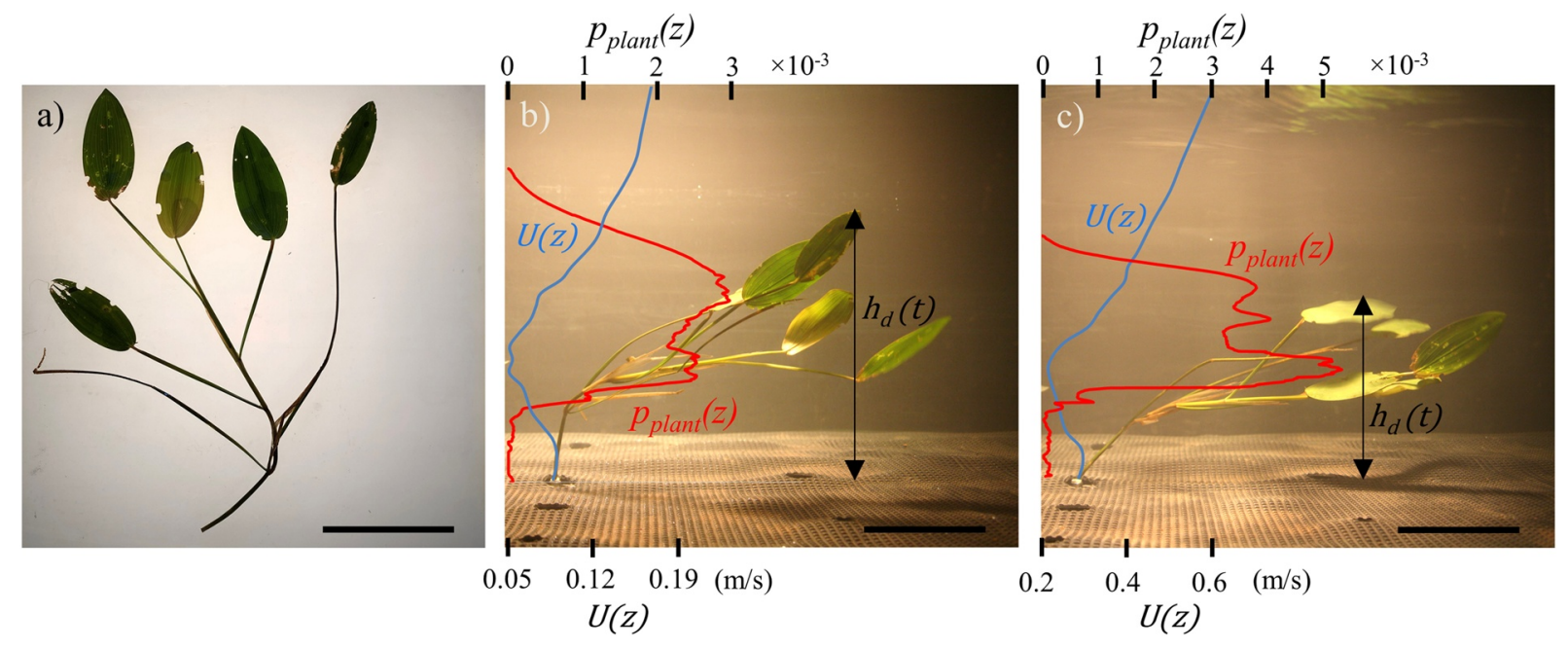

Figure 2. Images of a specimen from Group B: (a) for morphological characterization; (b) during hydrodynamic test at the low flow scenario; and (c) during hydrodynamic test at the high flow scenario. The scale bar in $(\mathrm{a}-\mathrm{c})$ is $10 \mathrm{~cm}$. In (b and c) the vertical profile of the mean velocity $U(z)$ spatially averaged across the three locations $0.05 \mathrm{~m}$ upstream of the DFS (in blue) and the time-averaged vertical distribution of plant biomass $p_{\text {plant }}(z)$ (in red) are superimposed to the image and the instantaneous plant deflected height $h_{d}(t)$ is shown.

Additional experiments were conducted with a Dantec 3D Laser Doppler Anemometer (LDA) at the flow scenarios described in Table 2, and with an artificial vegetation element attached to the DFS, to obtain the vertical profiles of the mean velocity at three different lateral locations $0.05 \mathrm{~m}$ upstream of the DFS. The profiles were measured in the central cross-section, $0.05 \mathrm{~m}$ on its left and $0.1 \mathrm{~m}$ on its right (spatial inhomogeneity of the measurements was caused by the interference of the vegetation elements). The spatially averaged profiles across the three locations are shown in Figures $2 \mathrm{~b}$ and $2 \mathrm{c}$. The mean approach velocity (Table 2) used in the calculations of the drag coefficient was estimated as the depth-average of the profile shown in Figures $2 \mathrm{~b}$ and 2c. The LDA system consisted of a $4 \mathrm{~W}$ Argon-Ion laser and two probes (2D and 1D) with a focal length of $198 \mathrm{~mm}$ in water. The probes were mounted on a fully automated traverse system above the flume with a $30^{\circ}$ angle between them. For measurements at a water depth less than the focal length the probes were placed in a water-filled tank with a glass bottom to ensure that the laser beams traveled through water. Flow velocities were calculated using coincident LDA-velocity measurements via a transformation matrix using BSA Flow Software v5 (see Aberle, 2006 for LDA-setup). The vertical profiles were sampled every $10 \mathrm{~mm}$ between 5 and $150 \mathrm{~mm}$ from the bed and every $20 \mathrm{~mm}$ from that point onwards. Velocity measurements were collected with a frequency between 50 and $200 \mathrm{~Hz}$ over $30 \mathrm{~s}$.

\subsection{Plant Biomechanical and Morphological Characterization}

When hydrodynamic tests on plants were completed, plant biomechanical and morphological traits were characterized by (a) taking a photograph of each plant spread out flat on a light table (Figure 2a) and (b) conducting three-point flexural tests on stem samples. Morphological characteristics such as length $(l)$, one-sided leaf surface area $\left(A_{\text {leaf }}\right)$ and total (i.e., two-sided) wetted surface area $\left(A_{w}\right)$ were obtained from the photographs using image analysis implemented with a MATLAB ${ }^{\circledast}$ routine. Three-point flexural tests were conducted manually with an apparatus purposely built in-house. The apparatus consisted of two identical quasi-frictionless wheels set $50 \mathrm{~mm}$ apart and mounted at the same vertical level on a horizontal beam with their rotational axis parallel to the horizontal plane. At the center of the beam, equidistant from the wheels, a manual distance measuring gauge allowed measuring the deflection of a stem sample supported by the wheels.

From each plant two stem samples were prepared, one from the bottom and one from the top of the plant, and their length and average diameter were measured with a ruler $( \pm 1 \mathrm{~mm})$ and a micrometer $( \pm 0.01 \mathrm{~mm})$. At the beginning of the test, the stem sample was set on the apparatus in such a way that its center was aligned with the distance measuring gauge. Then, the sample was loaded in its center using a range of known weights and for each weight the vertical displacement $(\Delta)$ of the sample associated with the applied 
force $(W)$ was measured with the gauge. Each sample was loaded with four different weights so that it was possible to estimate the slope $(W / \Delta)$ of the force-displacement curve and, from it, the flexural rigidity $\left(E_{b} I\right)$ according to:

$$
E_{b} I=\frac{s^{3}}{48} \frac{W}{\Delta}
$$

where $s$ is the sample span (i.e., the distance between the supports; in this case $50 \mathrm{~mm}$ e.g., Niklas, 1992). Based on visual observations of the stems, the calculation of the second moment of area $(I)$ of the stems was conducted considering a circular cross-section for the bottom parts (i.e., $I=\pi / 4 D^{4}$ ) and a semicircular cross-section with respect to an axis passing through the centroid for the top parts (i.e., $I=0.11 D^{4} / 16$ ), where $D$ is the cross-section diameter. Prior to three-point flexural tests, samples were kept in water and, during the tests, they were kept moistened so that their flexural rigidity would not be affected by the tests being conducted in air (Łoboda et al., 2018).

\subsection{Data Analysis}

The recorded videos were analyzed with a MATLAB ${ }^{\circledR}$ routine to extract the vertical distribution of plant biomass and plant deflected height in each frame. The first step in the routine consisted in removing the background (i.e., a frame with no plant) from the videos, then filters in the RGB channels were applied to remove any noise induced by non-homogenous light conditions so that only pixels containing parts of the plant (or outliers) remained. Potential outliers were erased by filtering out small disconnected objects and, thus, the position of the plant in each frame was obtained. The plant vertical distribution (or vertical distribution of plant biomass, $p_{\text {plant }}(z)$, see examples in Figures $2 \mathrm{~b}$ and $2 \mathrm{c}$ ) was then estimated as the time-averaged position of a plant in each vertical coordinate normalized by the mean plant surface area extracted from the videos. From the plant vertical distribution, the height of the plant centroid $\left(h_{c}\right)$ was calculated. Similarly, plant deflected height $\left(h_{d}\right)$ was estimated as the time-average vertical position of the highest point of the plant.

For the purposes of statistical analysis, the time-averaged deflected height $\left(h_{d}\right)$ and centroid height $\left(h_{c}\right)$ were normalized using the plant length $(l)$. The mean streamwise velocity $\left(U_{z}\right) 0.05$ m upstream of the DFS was calculated by numerical integration of the measured double-averaged vertical profile (Figures $2 \mathrm{~b}$ and $2 \mathrm{c}$ ). For calculation of the drag coefficient $\left(C_{D}\right)$ we used the formulation reported in Equation 1, considering $U_{z}$ to be equivalent to the mean approach velocity $\left(U_{a}\right)$ and using the total (i.e., two-sided) wetted surface area $\left(A_{w}\right)$ obtained from photographs of plants as described in the previous subsection.

All data post-processing and statistical analyses were conducted using MATLAB ${ }^{\circledast}$ and significance for all analyses was set at $\alpha=0.05$. For all parameters of interest (e.g., $F_{V} / F_{M}, E_{b} I$, and $C_{D}$ ) normality and homoscedasticity were assessed using the Kolmogorov-Smirnov and the Brown-Forsythe tests, respectively. In all cases the probability distributions were significantly different from the normal distribution. However, because the distribution shape was consistent between groups and variance was homogeneous across groups, we used analysis of variance and the Tukey's post-hoc comparison test corrected with Bonferroni technique for testing differences between plant groups. It is noteworthy that qualitatively similar results for all parameters of interest were obtained using the Kruskal-Wallis test by rank and Dunn's post-hoc comparison test. In Section 3.4 potential association between plant stress and hydrodynamics independently of plant group was assessed by analyzing the residual variance in a power-law regression model of $C_{D}$ as a function of $R e_{A}$ (such as that proposed by Wu et al. [1999]) against $F_{V} / F_{M}$ using a robust linear regression model.

\section{Results}

\subsection{Plant Stress}

In this study we used the maximum quantum yield $\left(F_{V} / F_{M}\right)$ of PSII as an indicator of plant stress. For the tested $P$. natans specimens, $F_{V} / F_{M}$ ranged between 0.69 and 0.79 (even though values below 0.73 are outliers, Figure 3a). Recalling that values of $F_{V} / F_{M}$ close to 0.83 are found in healthy plants, this range is comparable to the values reported by Hanelt et al. (2006) and Vettori and Rice (2020) for freshwater macrophytes of the Potamogeton family. The difference in plant stress across groups was significant (Table 3), 

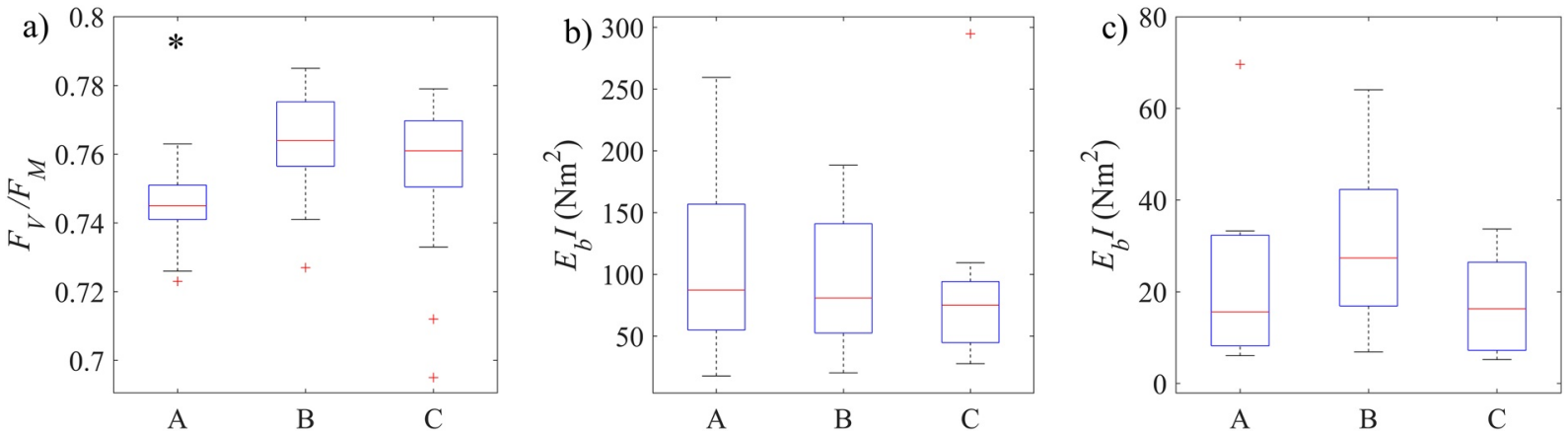

Figure 3. Results of Tukey's post-hoc comparisons corrected with the Bonferroni technique across Groups A, B, and C for: (a) maximum quantum yield of PSII; (b) flexural rigidity of stems at the bottom of plants; (c) flexural rigidity of stems at the top of plants. An asterisk indicates that a group is significantly different from the others.

with plants belonging to Group A characterized by lower values of $F_{V} / F_{M}$ compared to plants of Groups B and $\mathrm{C}$ (Figure 3a).

\subsection{Plant Biomechanical and Morphological Traits}

Biomechanical and morphological characterization of plants considered: flexural rigidity $\left(E_{b} I\right)$ and diameter $(d)$ of plant stems at the bottom and top of plants; plant length $(l)$; wetted surface area $\left(A_{w}\right)$; one-sided

Table 3

Results of Comparisons of Various Parameters Across Groups Performed With 1-Way Analysis of Variance and, Where Relevant, Post-hoc Tukey's Test With the Bonferroni Correction

\begin{tabular}{|c|c|c|c|c|}
\hline \multirow[b]{2}{*}{ Plant stress } & \multirow{2}{*}{$\frac{\text { Parameters }}{F_{V} / F_{M}}$} & \multicolumn{2}{|c|}{ 1-way ANOVA } & \multirow{2}{*}{$\begin{array}{c}\text { Tukey's HSD } \\
\mathrm{A}<\mathrm{B}(p<<0.01)\end{array}$} \\
\hline & & $\mathrm{F}_{2,78}=8.82$ & $p<<0.01$ & \\
\hline & & & & $\mathrm{A}<\mathrm{C}(p=0.022)$ \\
\hline \multirow[t]{8}{*}{ Plant biomechanical and morphological traits } & $d_{\text {top }}$ & $\mathrm{F}_{2,23}=0.43$ & $p=0.654$ & ॥ \\
\hline & $d_{\text {bot }}$ & $\mathrm{F}_{2,23}=0.14$ & $p=0.871$ & ॥ \\
\hline & $l$ & $\mathrm{~F}_{2,23}=0.50$ & $p=0.611$ & ॥ \\
\hline & $E I_{\text {top }}$ & $\mathrm{F}_{2,23}=1.11$ & $p=0.348$ & II \\
\hline & $E I_{\text {bot }}$ & $\mathrm{F}_{2,23}=0.11$ & $p=0.898$ & II \\
\hline & $A_{w}$ & $\mathrm{~F}_{2,23}=4.81$ & $p=0.019$ & $\mathrm{~A}>\mathrm{C}(p=0.017)$ \\
\hline & $A_{\text {leaf }}$ & $\mathrm{F}_{2,23}=3.46$ & $p=0.050$ & $\mathrm{~A}>\mathrm{C}(p=0.055)$ \\
\hline & $n_{\text {leaf }}$ & $\mathrm{F}_{2,23}=0.11$ & $p=0.896$ & ॥ \\
\hline \multirow[t]{10}{*}{ Plant hydrodynamics } & $h_{d}-$ Run 1 & $\mathrm{~F}_{2,23}=0.89$ & $p=0.425$ & ॥ \\
\hline & $h_{d}-$ Run 2 & $\mathrm{~F}_{2,23}=0.41$ & $p=0.666$ & ॥ \\
\hline & $h_{c}-$ Run 1 & $\mathrm{~F}_{2,23}=0.05$ & $p=0.951$ & ॥ \\
\hline & $h_{c}-$ Run 2 & $\mathrm{~F}_{2,23}=0.45$ & $p=0.830$ & ॥ \\
\hline & $F_{D}-$ Run 1 & $\mathrm{~F}_{2,23}=2.36$ & $p=0.120$ & ॥ \\
\hline & $F_{D}-$ Run 2 & $\mathrm{~F}_{2,23}=2.11$ & $p=0.150$ & ॥ \\
\hline & $C_{D}-$ Run 1 & $\mathrm{~F}_{2,23}=5.36$ & $p=0.013$ & $\mathrm{~A}<\mathrm{B}(p=0.019)$ \\
\hline & & & & $\mathrm{A}<\mathrm{C}(p=0.053)$ \\
\hline & $C_{D}-$ Run 2 & $\mathrm{~F}_{2,23}=5.82$ & $p=0.010$ & $\mathrm{~A}<\mathrm{B}(p=0.033)$ \\
\hline & & & & $\mathrm{A}<\mathrm{C}(p=0.017)$ \\
\hline
\end{tabular}

Note. The symbols indicate: maximum quantum yield of photosystem II $F_{V} / F_{M}$; diameter of stem's top part $d_{\text {top }}$; diameter of stem's bottom part $d_{\text {bot }}$; length of plant $l$; flexural rigidity of stem's top part $E I_{\text {top }}$; flexural rigidity of stem's bottom part $E I_{\text {bot }}$; wetted surface area $A_{w}$; leaves surface area $A_{\text {leaf }}$; number of leaves $n_{\text {leaf }}$; plant deflected height $h_{d}$; plant centroid height $h_{c}$; mean drag force $F_{D}$; drag coefficient $C_{D}$. 

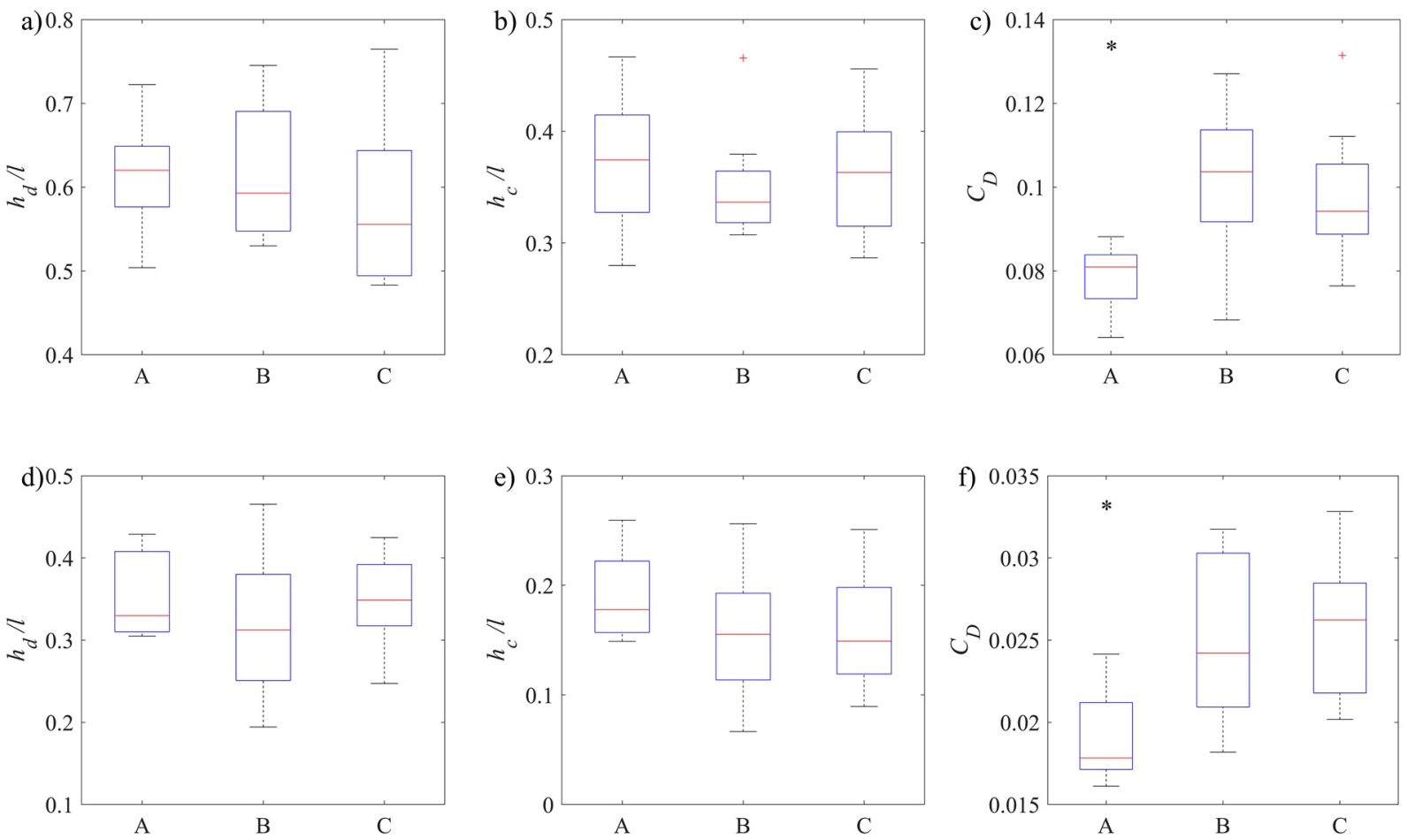

Figure 4. Results of Tukey's post-hoc comparisons corrected with the Bonferroni technique across Groups A, B, and C for: (a-d) dimensionless plant deflected height; (b-e) dimensionless plant mean height; (c-f) the drag coefficient. The top row reports values at the low flow scenario, the bottom row at the high flow scenario. An asterisk indicates that a group is significantly different from the others.

leaf surface area $\left(A_{\text {leaf }}\right)$; and number of leaves $\left(n_{\text {leaf }}\right)$. These parameters were used because they contribute to defining the hydrodynamic forces acting on plants, $E_{b} I$ being the most important in our analysis. The flexural rigidity of plant stems ranged from $17 \mathrm{Nm}^{2}$ to $300 \mathrm{Nm}^{2}$ for the bottom of plants and from 6 to 70 $\mathrm{Nm}^{2}$ for the top parts (Figures $3 \mathrm{~b}$ and $3 \mathrm{c}$ ). For all parameters considered, no significant differences were found across groups (Table 3), but the wetted surface area and the one-sided leaf surface area were larger for Group A compared to Group C.

\subsection{Plant Hydrodynamics}

The hydrodynamic performance of plant specimens was assessed with the dimensionless plant deflected height $\left(h_{d} / l\right)$, the dimensionless plant centroid height $\left(h_{c} / l\right)$ and the drag coefficient $\left(C_{D}\right)$ calculated using Equation 1. The dimensionless plant deflected height varied within the ranges $0.48-0.77$ and $0.19-0.47$ in the two flow scenarios investigated (Figures $4 \mathrm{a}$ and $4 \mathrm{~d}$ ), while $h_{c} / l$ ranged within $0.28-0.47$ and $0.07-0.26$, respectively (Figures $4 \mathrm{~b}$ and $4 \mathrm{e}$ ). The drag coefficient varied between $0.06-0.13$ and $0.016-0.033$ at the low and high flow scenarios, respectively (Figures $4 \mathrm{c}$ and $4 \mathrm{f}$ ).

No differences across groups were identified for the dimensionless plant deflected height (Figures 4a and 4d) or plant centroid height (Figures $4 \mathrm{~b}$ and $4 \mathrm{e}$ ) in either flow scenario, suggesting that plant reconfiguration was independent of the groups. It is important to note that also the (dimensional) plant deflected height $\left(h_{d}\right)$ and centroid height $\left(h_{c}\right)$ were not characterized by significant differences across groups (Table 3 ). However, the drag coefficient for plants of Group A was significantly different from that for plants of other groups at both flow scenarios (Table 3). Results of Tukey's post-hoc comparisons corrected with the Bonferroni technique show that $C_{D}$ for Group A is lower than for Groups B and C with $p=0.02-0.05$ for the low flow scenario and $p=0.02-0.03$ for the high flow scenario (Figures $4 \mathrm{c}$ and $4 \mathrm{f}$ ). 

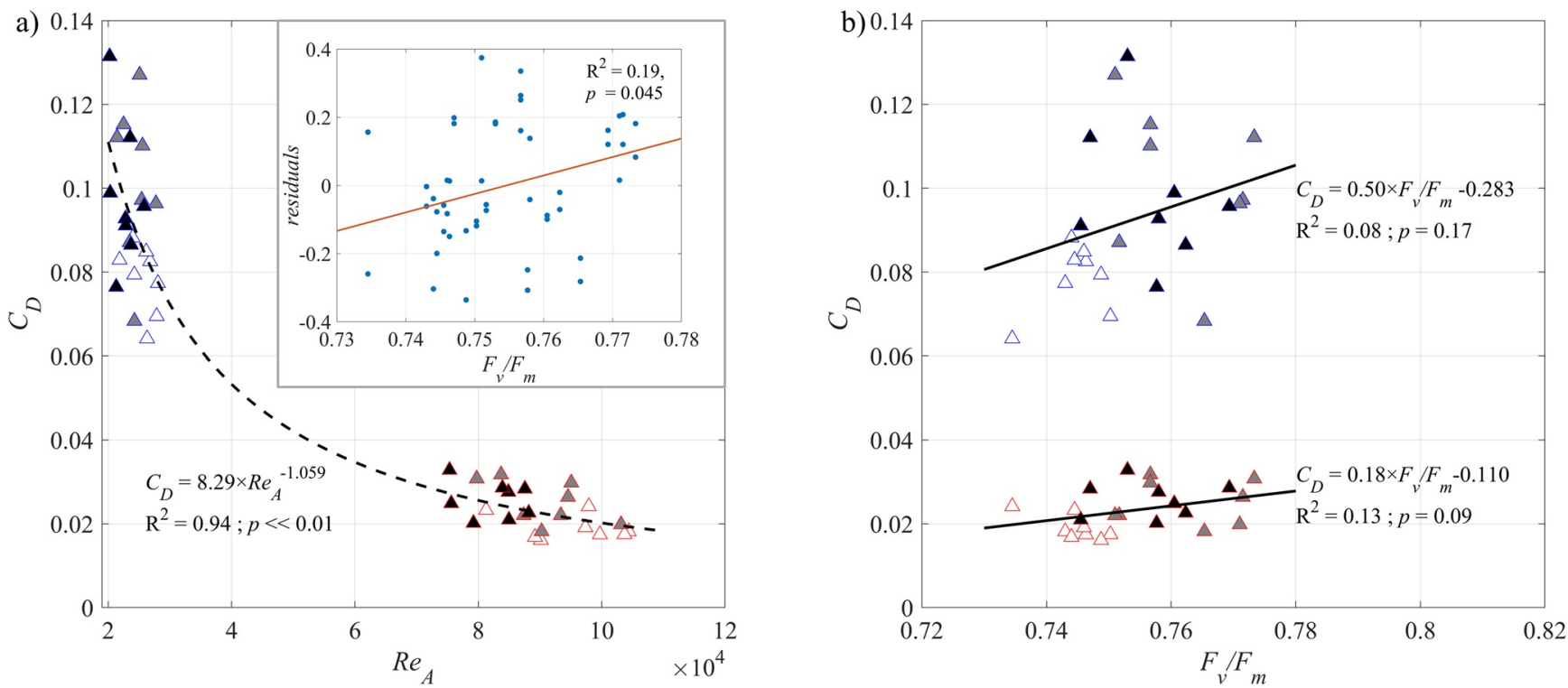

Figure 5. The drag coefficient of specimens of $P$. natans as a function of: (a) the plant Reynolds number defined using the total wetted surface area of plants (i.e., $R e_{A}=U_{a} \sqrt{A_{w}} / v$ ) and (b) the average (across all leaves tested) maximum quantum yield of PSII for each plant. For a clearer presentation, different colors are used for different flow scenarios (blue for low flow scenario and red for high flow scenario) and different symbol shading are used for different groups (white for Group A, gray for Group B and black for Group C). In panel (a) the black dashed line refers to the power-law regression (whose expression and relevant statistical information are reported) and the inset displays its residuals against $F_{V} / F_{M}$ and the linear regression (with relevant statistical information) between them. In panel (b) the solid black lines refer to the linear regressions for both flow scenarios (expressions and relevant statistical information are reported).

\subsection{Linking Plant Stress and Hydrodynamics of Individual Plants}

The potential link between plant stress and hydrodynamics of individual plants was first investigated by plotting the drag coefficient $\left(C_{D}\right)$ as a power-law function of the plant Reynolds number $\left(R e_{A}\right)$ (Figure $\left.5 \mathrm{a}\right)$. The relationship thus obtained describes the variance in the data very well $\left(R^{2}=0.94\right)$ and is strongly significant. Even though they show a large variance, the residuals of the power-law regression are significantly correlated with $F_{V} / F_{M}\left(p=0.045\right.$; inset of Figure 5a), suggesting that part of the variance in $C_{D}$ that cannot be ascribed to $R e_{A}$ is linked to $F_{V} / F_{M}$. In more detail, it appears that higher values of $F_{V} / F_{M}$ are associated with values of $C_{D}$ larger than what predicted by the power-law model.

Moreover, we plotted the drag coefficient as a function of the average maximum quantum yield $\left(F_{V} / F_{M}\right)$ of PSII for both flow scenarios (Figure $5 \mathrm{~b}$ ). While $C_{D}$ does not have a clear correlation with $F_{V} / F_{M}$ for the low flow scenario, for the high flow scenario the correlation between the parameters is marginally significant $(p=0.09$, Figure 5b).

\section{Discussion}

\subsection{Plant Physiological and Biomechanical Response}

The maximum quantum yield of PSII $\left(F_{V} / F_{M}\right)$, a proxy of plant stress, was significantly lower for Group A than for Groups B and C (Figure 3a). Since Group A was the reference group originally designed to minimize plant stress while Groups $\mathrm{B}$ and $\mathrm{C}$ were designed to generate stress on plants, this result is unexpected. To explain it, two possibilities exist: plants were exposed to stressful conditions in the field and recovered during the storage in the laboratory, or plants in Group A still showed a transient stress response caused by moving them from the field to the laboratory-whereas Groups B and C had sufficient time to adapt to the laboratory conditions. To corroborate the first possibility, we note that the conditions at the site were particularly warm in the days prior to collection (see temperature at the time of collection in Table 1). Even though the tolerance to thermal variations of freshwater macrophytes is mostly unknown, Chalanika De Silva \& Asaeda (2017) reported an increase in oxidative damage and a decrease in 
the growth rate of three species of freshwater macrophytes when water temperature exceeded $25-30^{\circ} \mathrm{C}$. These effects were measured $48 \mathrm{~h}$ after the exposure to high temperature treatment, a time period similar to the one employed in the current study for Group A. Further, a number of works on terrestrial plants found that plant photosynthetic activities are negatively affected when temperature exceeds a species-dependent maximum threshold (e.g., Wahid et al., 2007). This impact is particular evident in the activity of PSII and causes a significant reduction in the maximum quantum yield of PSII (Yamada et al., 1996). Unfortunately, because we did not monitor $F_{V} / F_{M}$ of all groups in time, we cannot identify the cause of this difference in $F_{V} / F_{M}$ with certainty.

It is also worth noting that the light conditions in all group mesocosms are below the optimal for plant growth; for instance Smart and Barko (1985) suggested using PAR levels above $300 \mu \mathrm{mol}_{\text {photon }} / \mathrm{m}^{2} / \mathrm{s}$. However, in previous works with submerged freshwater macrophytes PAR levels between 20 and $120 \mu \mathrm{mol}_{\text {photon }} /$ $\mathrm{m}^{2} / \mathrm{s}$ were employed (e.g., Chalanika De Silva \& Asaeda, 2017; Hanelt et al., 2006; Marwood et al., 2001), and levels as low as $50 \mu \mathrm{mol}_{\text {photon }} / \mathrm{m}^{2} / \mathrm{s}$ are common in hydraulic laboratories when dedicated lighting units are installed (see Table 1 in Vettori \& Rice, 2020). Moreover, the light compensation point for various freshwater macrophytes has been reported between 2 and $23 \mu \mathrm{mol}_{\text {photon }} / \mathrm{m}^{2} / \mathrm{s}$ within a $16 \mathrm{~h}: 8 \mathrm{~h}$ day $/$ night cycle (Eller et al., 2015; Sand-Jensen \& Madsen, 1991). Therefore, we are confident that the PAR levels used for Groups A and B are above the light compensation point for P. natans, while they are below it for Group C. As a consequence, we expect that plants of Group $C$ would have deteriorated soon after the tests because of light conditions inadequate for photosynthesis.

Regardless of its origin - that is, transient stress or stress induced by conditions in the field, the difference in $F_{V} / F_{M}$ between Group A and Groups B and C is approximately $2 \%-3 \%$; thus it appears to be associated with non-severe conditions. Indeed, previous studies with freshwater macrophytes found reductions in $F_{V} /$ $F_{M}$ between $10 \%$ and 30\% when plant were exposed to severe conditions (e.g., Hanelt et al., 2006; Marwood et al., 2001).

Biomechanical properties across groups did not show significant variations in contrast with findings reported in Vettori and Rice (2020). In this study estimates of the stem flexural rigidity were obtained from data collected with tests manually conducted with an apparatus built in-house and whose accuracy is certainly lower than that of professional benchtop testing machines such as those used by Miler et al. (2012) or Vettori and Rice (2020). Indeed, the coefficient of variation associated with the estimates of stem flexural rigidity in this study is between $60 \%$ and $90 \%$, while it ranged between $30 \%$ and $45 \%$ for another species of the Potamogeton family in Vettori and Rice (2020). Therefore, it is possible, even though unlikely, that no differences in stem flexural rigidity were identified because of the low accuracy of the mechanical tests. However, considering the findings of the hydrodynamic experiments-namely, no difference in plant deflected height and centroid height across groups (Table 3)-we argue that the potential effect of this inaccuracy in the biomechanical tests on the results is unimportant. It is also worth noting that a distinction in flexural rigidity between top and bottom of plant stems has been identified in the current study, in agreement with previous works on freshwater macrophytes (e.g., Miler et al., 2012; Vettori \& Rice, 2020).

The only significant differences in the morphological traits were found between Groups A and C, with the wetted surface area (and leaf surface area) of the former being larger than the that of the latter. This difference, though, was likely caused by plant allocation into group mesocosms rather than being associated with the different laboratory conditions, as it is not probable that the surface area of leaves would reduce significantly within a few days.

\subsection{Plant Hydrodynamic Performance}

The values of the drag coefficient experienced by specimens of $P$. natans (Figure 5) vary within the range $0.016-0.13$, which is compatible with the range between 0.02 and 0.065 reported by Siniscalchi and Nikora (2012) for five macrophyte species at similar plant Reynolds numbers $\left(R e_{A}=4-10 \times 10^{4}\right)$. Bal et al. (2011) carried out experiments with specimens of $P$. natans at flow conditions analogous to those used in the present study, namely mean flow velocity between 0.01 and $0.37 \mathrm{~m} / \mathrm{s}$ and water depth of $0.3 \mathrm{~m}$. They reported values of the mean drag force $F_{D}$ per one-sided surface area of approximately 2 and $7 \mathrm{~N} / \mathrm{m}^{2}$ for flow scenar- 
ios similar to those used in the present study. Calculating the same parameter from our data, we found that the mean drag force per one-sided surface area was $0.7-1.4 \mathrm{~N} / \mathrm{m}^{2}$ at the low flow scenario and $2.5-5.1 \mathrm{~N} / \mathrm{m}^{2}$ at the high flow scenario. The lower values reported in the present study are likely associated with the tested plants being located within a canopy, while Bal et al. (2011) conducted experiments with isolated plants. We can therefore deduce that the specimens we used for hydrodynamic tests performed similarly to the freshwater macrophytes used in earlier works - namely, they are representative of standard experiments carried out in hydraulic facilities. Unfortunately, no studies that specifically report the drag coefficient $C_{D}$ of $P$. natans are available.

Plants in Group A were characterized by a drag coefficient significantly lower than that for plants in Groups $\mathrm{B}$ and $\mathrm{C}$, with a difference in the group's mean $C_{D}$ of approximately $30 \%$. Since $C_{D}$ was different across groups but plant deflected height and centroid height (both dimensional and dimensionless) were not, we deduce that the variation in the drag force associated with the groups was not caused by a different plant posture or reconfiguration. In other words, plants of Group A were not bent closer to the bed compared to the others, a strategy that would reduce the approach velocity (see velocity profiles in Figures $2 \mathrm{~b}$ and $2 \mathrm{c}$ ) and the frontal area exposed to the incoming flow.

\subsection{Linking Plant Stress and Hydrodynamics}

In the context of a potential link between plant stress and hydrodynamics, first we note that the same significant differences across groups (i.e., A vs. B and C) are identified for the maximum quantum yield $\left(F_{V} /\right.$ $F_{M}$ ) of PSII and the drag coefficient $\left(C_{D}\right)$, with lower drag coefficients experienced by plants showing higher levels of stress (Figures 3 and 4). It is possible that $C_{D}$ for Group A was smaller than for Group C because their mean drag force $\left(F_{D}\right.$, Table 3$)$ were undistinguishable, while the wetted surface area $\left(A_{w}\right.$, Table 3$)$ for Group A was larger than that for Group C-recalling that $C_{D} \propto f\left(F_{D} / A_{w}\right)$ (see Equation 1). However, this reasoning would not explain the difference in $C_{D}$ between Groups $\mathrm{A}$ and $\mathrm{B}$. Therefore, we argue that there may be a causal association between $C_{D}$ and $F_{V} / F_{M}$.

To corroborate such a hypothesis, we analyzed the data of all plants tested independent of their allocation group and a marginal correlation between $C_{D}$ and $F_{V} / F_{M}$ was found for the high flow scenario (Figure $5 \mathrm{~b}$ ). Further, $F_{V} / F_{M}$ was found to be significantly correlated with the residuals of the power-law model between the drag coefficient and plant Reynolds number (which included both flow scenarios), suggesting that $F_{V} /$ $F_{M}$ can describe part of the variance left in $C_{D}$ once the effect of $R e_{A}$ is accounted for. It is also worth noting that the slope of the linear regression between $F_{V} / F_{M}$ and the residuals is positive, indicating that $C_{D}$ of healthier plants is biased high compared to the prediction of the model (and the opposite applies for stressed plants).

It is likely that the reason for this partial inconsistency in results between pooled and individual plant data lies in the high variability of $F_{V} / F_{M}$. To investigate this further, we verified that the within-plant variance (based on the multiple measurements per plant taken) was larger than the within-group variance using analysis of variance for each group. This result is a natural consequence of the spatial heterogeneity of plant photosynthetic performance (Baker, 2008; Murchie \& Lawson, 2013); in other words, even though the predawn $F_{V} / F_{M}$ is a stable fluorescence parameter, it is dependent on the leaves and the position within each leaf where measurements are taken.

It is therefore possible that our treatments were not sufficiently severe to induce a variation in $F_{V} / F_{M}$ comparable to the variance inherent to photosynthetic spatial heterogeneity across the plants (see Section 4.1). However, by analyzing the pooled data this variability would reduce and the effects of treatments become more significant/visible. Additionally, $F_{V} / F_{M}$ could be intrinsically linked to a biomechanical trait not measured in the current study that is controlled by processes linked to photosynthesis. Indeed, a global analysis of leaf biomechanics in trees revealed that local environmental conditions, that are known to affect plant health status, have a strong influence in leaf biomechanics (Onoda et al., 2011). Given that a similar finding was reported for seagrasses (Vettori \& Marjoribanks, 2021), this could be the case for freshwater macrophytes too. Because earlier works have concluded that foliage makes a considerable contribution to the total drag force experienced by a plant (e.g., Aberle \& Järvelä, 2013; Bal et al., 2011), it is possible that leaf 
biomechanics regulates the drag force of freshwater macrophytes in a way similar to that of seagrass blades (Vettori \& Marjoribanks, 2021).

In our previous work (Vettori \& Rice, 2020) we tested how freshwater macrophytes respond to laboratory conditions typical of hydraulic facilities in terms of plant stress and stem mechanical properties. We found that it is quite common for plants to be stressed in laboratory settings and that higher levels of plant stress are associated with plant stems being more pliant, from which we hypothesized that even shortterm inappropriate plant husbandry can potentially affect the results of hydrodynamic experiments. The present study seems to verify this hypothesis by suggesting that some link exists between plant stress and hydrodynamics. In more detail, the results described herein indicate that more stressed plants experience lower drag forces. Since the differences across groups appear to be associated with the different time and conditions of storage of plants, this study provides first indications that the period and nature of plant storage prior to experiments can impact on plant hydrodynamics. While this may sound obvious when considering large temporal scales (i.e., months, years), the fact that this impact can be significant at temporal scales relevant to laboratory experiments (i.e., days to weeks) is of relevance for hydraulic practitioners. Based on the results of our study, we infer that in previous works the drag force or flow resistance of vegetation may have been underestimated because of high levels of plant stress in the specimens used for flume experiments.

In the light of these findings, a better characterization of environmental conditions in the field and laboratory storage conditions is desirable. However, it is also important to bear in mind that the effects of environmental stressors vary considerably depending on the plant species and phenotypes. For example, in the present study the highest stress and lowest drag force were reported for the group that was stored for the shortest period of time (i.e., Group A), probably because plants were exposed to very high temperature in the field. On the other hand, there was no significant effect caused by very low light conditions within an 8-day period (i.e., Group B vs. Group C). For this reason, we believe using an indicator of plant stress able to indicate how healthy plants are, independently of the specific conditions, is advantageous. The proxy of plant health status used herein was characterized by a large variability that, to some extent, impacted on the significance of our results. Parameters used for studying plant signal networks may work better at linking plant stress and hydrodynamics, also because they are more directly correlated with the development of plant tissues. For example, hydrogen peroxide and other reactive oxygen species have been used successfully by Asaeda et al. (2017) and Asaeda and Rashid (2017) to assess the effect of abiotic stressors on plant health.

Different conditions and time of storage can be associated with a variation of about $30 \%$ in the mean drag coefficient of the groups considered herein. To contextualize this impact, it is useful to compare it with the drag variability due to plant species found in earlier laboratory studies with freshwater macrophytes. At hydraulic conditions similar to those used in the current study, the variability associated with the plant species was approximately $15 \%-20 \%$ in the mean drag force per plant one-sided surface area in Bal et al. (2011) and between $30 \%$ and 50\% in the drag coefficient in Siniscalchi et al. (2012). Therefore, the impact of conditions and time of storage can be as important as that associated with the use of different plant species. Since biomechanical response of plants to environmental stressors takes effect in a few days, if plants are used in flume tests soon after collection we expect their performance to be close to that they would have at the collection site, even though the potential effect of transient stress is still unknown. On the contrary, when plants are used in tests after being exposed for several days to new conditions, the results of flume tests will be influenced by plant adaptation. This does not imply that plants should always be tested at optimal conditions (i.e., lowest stress levels), instead it highlights the need for results to be put in the correct environmental context, which goes beyond simple identification of species and seasonality.

This study was focused on a freshwater macrophyte, a type of vegetation that is flexible and characterized by non-woody tissues. Nevertheless, we expect the same behavior to occur in other types of aquatic vegetation, such as marine and saltmarsh plants, within their own timeframes. In the case of plants largely comprised of woody tissues (e.g., riparian trees), we anticipate that the effect of laboratory and storage conditions will still be evident because of the large contribution of foliage to the drag force. 


\section{Conclusions}

This paper presents a multidisciplinary study, based on laboratory experiments conducted with a freshwater macrophyte (P. natans), that assesses the effects of storage conditions typical of hydraulic laboratories on: plant stress, using chlorophyll fluorescence analysis; plant biomechanical and morphological traits, via 3-point flexural tests and morphological characterization; and plant hydrodynamic performance, using data collected during flume experiments. Results indicate that the conditions in which plants are stored and the period of storage can influence plant stress and hydrodynamics significantly. The treatment causing the highest stress to plants is also associated with the best hydrodynamic performance (i.e., lowest drag coefficient), therefore suggesting a potential link between plant stress and hydrodynamics. The mean drag coefficient across the most stressed plants was approximately 30\% lower than that across the healthiest plants; quantitatively, this effect is comparable to differences in drag force between species of freshwater macrophytes reported in previous studies. Even though the proxy of plant stress used in the current study was not found to be strongly correlated with the drag coefficient of individual plants, using tools developed in plant physiology to monitor plant stress can help manage plant use in laboratory settings and avoid bias associated with plants being unhealthy.

\section{Conflict of Interest}

The authors declare no conflicts of interest relevant to this study.

\section{Data Availability Statement}

Data supporting the findings and conclusions of this publication are deposited in the open access repository Zenodo at the following link: https://doi.org/10.5281/s.

Acknowledgments

D. Vettori and S. Rice acknowledge financial support of the European Community's Horizon 2020 Programme (through the grant of the Integrated Infrastructure Initiative HYDRALAB+, Contract no. 654110). D. Vettori is grateful to P. Y. Henry for helpful discussions during the design phase of this study and to the whole team of the Division of Hydraulic Engineering and River Morphology at the Leichtweiß-Institut for Hydraulic Engineering and Water Resources, Technische Universität Braunschweig, for making him feel at home during his time in Braunschweig. The authors would like to thank the anonymous reviewers whose very insightful comments helped to improve the quality of the manuscript. Open access funding enabled and organized by Projekt DEAL.

\section{References}

Aberle, J. (2006). Spatially averaged near-bed flow field over rough armor layers. In International Conference on Fluvial Hydraulics River Flow (pp. 153-162). https://doi.org/10.1201/9781439833865.ch14

Aberle, J., \& Järvelä, J. (2013). Flow resistance of emergent rigid and flexible floodplain vegetation. Journal of Hydraulic Research, 51(1), 33-45. https://doi.org/10.1080/00221686.2012.754795

Armanini, A., Righetti, M., \& Grisenti, P. (2005). Direct measurement of vegetation resistance in prototype scale. Journal of Hydraulic Research, 43(5), 481-487. https://doi.org/10.1080/00221680509500146

Asaeda, T., \& Rashid, M. H. (2017). Effects of turbulence motion on the growth and physiology of aquatic plants. Limnologica, 62, $181-187$. https://doi.org/10.1016/j.limno.2016.02.006

Asaeda, T., Sanjaya, K., \& Kaneko, Y. (2017). Effects of mechanical stressors caused by mean flow and turbulence on aquatic plants with different morphologies. Ecohydrology, 10, 1-13. https://doi.org/10.1002/eco.1873

Baker, N. R. (2008). Chlorophyll fluorescence: A probe of photosynthesis in vivo. Annual Review of Plant Biology, 59, 89-113. https://doi. org/10.1146/annurev.arplant.59.032607.092759

Baker, N. R., \& Rosenqvist, E. (2004). Applications of chlorophyll fluorescence can improve crop production strategies: An examination of future possibilities. Journal of Experimental Botany, 55(403), 1607-1621. https://doi.org/10.1093/jxb/erh196

Bal, K., Bouma, T. J., Buis, K., Struyf, E., Jonas, S., Backx, H., \& Meire, P. (2011). Trade-off between drag reduction and light interception of macrophytes: Comparing five aquatic plants with contrasting morphology. Functional Ecology, 25(6), 1197-1205. https://doi. org/10.1111/j.1365-2435.2011.01909.x

Bertoldi, W., Welber, M., Gurnell, A. M., Mao, L., Comiti, F., \& Tal, M. (2015). Physical modelling of the combined effect of vegetation and wood on river morphology. Geomorphology, 246, 178-187. https://doi.org/10.1016/j.geomorph.2015.05.038

Biggs, H. J., Nikora, V., Gibbins, C. N., Fraser, S., Green, D. R., Papadopoulos, K., \& Hicks, D. M. (2018). Coupling Unmanned Aerial Vehicle (UAV) and hydraulic surveys to study the geometry and spatial distribution of aquatic macrophytes. Journal of Ecohydraulics, 3(1), 1-58. https://doi.org/10.1080/24705357.2018.1466666

Chalanika De Silva, C. H., \& Asaeda, T. (2017). Effects of heat stress on growth, photosynthetic pigments, oxidative damage and competitive capacity of three submerged macrophytes. Journal of Plant Interactions, 12(1), 228-236. https://doi.org/10.1080/17429145.2017.1 322153

Cornacchia, L., Licci, S., Nepf, H. M., Folkard, A. M., van der Wal, D., van de Koppel, J., et al. (2019). Turbulence-mediated facilitation of resource uptake in patchy stream macrophytes. Limnology and Oceanography, 64(2), 714-727. https://doi.org/10.1002/lno.11070

Cornacchia, L., Van De Koppel, J., Van Der Wal, D., Wharton, G., Puijalon, S., \& Bouma, T. J. (2018). Landscapes of facilitation: How self-organized patchiness of aquatic macrophytes promotes diversity in streams. Ecology, 99(4), 832-847. https://doi.org/10.1002/ecy.2177

Eller, F., Alnoee, A. B., Boderskov, T., Guo, W., Kamp, A. T., Sorrell, B. K., \& Brix, H. (2015). Invasive submerged freshwater macrophytes are more plastic in their response to light intensity than to the availability of free $\mathrm{CO}_{2}$ in air-equilibrated water. Freshwater Biology, 60(5), 929-943. https://doi.org/10.1111/fwb.12547

Folkard, A. M. (2011). Vegetated flows in their environmental context: A review. Proceedings of the Institution of Civil Engineers - Engineering and Computational Mechanics, 164(1), 3-24. https://doi.org/10.1680/eacm.8.00006 
Gurnell, A. M. (2014). Plants as river system engineers. Earth Surface Processes and Landforms, 39(1), 4-25. https://doi.org/10.1002/ esp.3397

Hanelt, D., Hawes, I., \& Rae, R. (2006). Reduction of UV-B radiation causes an enhancement of photoinhibition in high light stressed aquatic plants from New Zealand lakes. Journal of Photochemistry and Photobiology B: Biology, 84, 89-102. https://doi.org/10.1016/j. jphotobiol.2006.01.013

Hussner, A., Hoelken, H. P., \& Jahns, P. (2010). Low light acclimated submerged freshwater plants show a pronounced sensitivity to increasing irradiances. Aquatic Botany, 93(1), 17-24. https://doi.org/10.1016/j.aquabot.2010.02.003

Infantes, E., Orfila, A., Simarro, G., Terrados, J., Luhar, M., \& Nepf, H. M. (2012). Effect of a seagrass (Posidonia oceanica) meadow on wave propagation. Marine Ecology Progress Series, 456, 63-72. https://doi.org/10.3354/meps09754

Jalonen, J., Järvelä, J., \& Aberle, J. (2013). Leaf area index as vegetation density measure for hydraulic analyses. Journal of Hydraulic Engineering, 139(5), 461-469. https://doi.org/10.1061/(ASCE)HY.1943-7900.0000700

James, R. K., Silva, R., van Tussenbroek, B. I., Escudero-Castillo, M., Mariño-Tapia, I., Dijkstra, H. A., et al. (2019). Maintaining tropical beaches with seagrass and algae: A promising alternative to engineering solutions. BioScience, 69(2), 136-142. https://doi.org/10.1093/ biosci/biy154

Lara, J. L., Maza, M., Ondiviela, B., Trinogga, J., Losada, I. J., Bouma, T. J., \& Gordejuela, N. (2016). Large-scale 3-D experiments of wave and current interaction with real vegetation. Part 1: Guidelines for physical modeling. Coastal Engineering, 107, 70-83. https://doi. org/10.1016/j.coastaleng.2015.09.012

Larsen, L. G. (2019). Multiscale flow-vegetation-sediment feedbacks in low-gradient landscapes. Geomorphology, 334, 165-193. https://doi. org/10.1016/j.geomorph.2019.03.009

Lei, J., \& Nepf, H. M. (2019). Wave damping by flexible vegetation: Connecting individual blade dynamics to the meadow scale. Coastal Engineering, 147, 138-148. https://doi.org/10.1016/j.coastaleng.2019.01.008

Łoboda, A. M., Przyborowski, Ł., Karpiński, M., Bialik, R. J., \& Nikora, V. (2018). Biomechanical properties of aquatic plants: The effect of test conditions. Limnology and Oceanography: Methods, 16(4), 222-236. https://doi.org/10.1002/lom3.10239

Marwood, C. A., Solomon, K. R., \& Greenberg, B. M. (2001). Chlorophyll fluorescence as a bioindicator of effects on growth in aquatic macrophytes from mixtures of polycyclic aromatic hydrocarbons. Environmental Toxicology and Chemistry, 20(4), 890-898. https://doi. org/10.1002/etc.5620200425

Maxwell, K., \& Johnson, G. N. (2000). Chlorophyll fluorescence-A practical guide. Journal of Experimental Botany, 51(345), 659-668. https://doi.org/10.1093/jexbot/51.345.659

Miler, O., Albayrak, I., Nikora, V., \& O'Hare, M. (2012). Biomechanical properties of aquatic plants and their effects on plant-flow interactions in streams and rivers. Aquatic Sciences, 74(1), 31-44. https://doi.org/10.1007/s00027-011-0188-5

Möller, I., Kudella, M., Rupprecht, F., Spencer, T., Paul, M., Van Wesenbeeck, B. K., et al. (2014). Wave attenuation over coastal salt marshes under storm surge conditions. Nature Geoscience, 7(10), 727-731. https://doi.org/10.1038/ngeo2251

Murchie, E. H., \& Lawson, T. (2013). Chlorophyll fluorescence analysis: A guide to good practice and understanding some new applications. Journal of Experimental Botany, 64(13), 3983-3998. https://doi.org/10.1093/jxb/ert208

Nepf, H. M. (2012). Hydrodynamics of vegetated channels. Journal of Hydraulic Research, 50(3), 262-279. https://doi.org/10.1080/00221 686.2012.696559

Niklas, K. J. (1992). Plant biomechanics: An engineering approach to plant form and function. University of Chicago Press.

Nikora, V. (2010). Hydrodynamics of aquatic ecosystems: An interface between ecology, biomechanics and environmental fluid mechanics. River Research and Applications, 26(4), 367-384. https://doi.org/10.1002/rra.1291

Onoda, Y., Westoby, M., Adler, P. B., Choong, A. M. F., Clissold, F. J., Cornelissen, J. H. C., et al. (2011). Global patterns of leaf mechanical properties. Ecology Letters, 14(3), 301-312. https://doi.org/10.1111/j.1461-0248.2010.01582.x

Sand-Jensen, K., \& Madsen, T. V. (1991). Minimum light requirements of submerged freshwater macrophytes in laboratory growth experiments. The Journal of Ecology, 79(3), 749-764. https://doi.org/10.2307/2260665

Schoneboom, T. (2011). Widerstand flexibler Vegetation und Sohlenwiderstand in durchströmten Bewuchsfeldern. Technische Universität Braunschweig. https://doi.org/10.24355/dbbs.084-201112141024-0

Schoneboom, T., Aberle, J., Wilson, C. A. M. E., \& Dittrich, A. (2008). Drag force measurements of vegetation elements. In Proceedings of the 8th International Conference on Hydro-Science and Engineering (ICHE) 2008. (Yen 2002), Papers on CD-ROM.

Siniscalchi, F., \& Nikora, V. (2012). Flow-plant interactions in open-channel flows: A comparative analysis of five freshwater plant species. Water Resources Research, 48(5), 1-13. https://doi.org/10.1029/2011WR011557

Siniscalchi, F., Nikora, V., \& Aberle, J. (2012). Plant patch hydrodynamics in streams: Mean flow, turbulence, and drag forces. Water Resources Research, 48(1), 1-14. https://doi.org/10.1029/2011WR011050

Smart, M. R., \& Barko, J. W. (1985). Laboratory culture of submersed freshwater macrophytes on natural sediments. Aquatic Botany, 21, 251-263. https://doi.org/10.1016/0304-3770(85)90053-1

Statzner, B., Lamouroux, N., Nikora, V., \& Sagnes, P. (2006). The debate about drag and reconfiguration of freshwater macrophytes: Comparing results obtained by three recently discussed approaches. Freshwater Biology, 51(11), 2173-2183. https://doi. org/10.1111/j.1365-2427.2006.01636.x

Tal, M., \& Paola, C. (2010). Effects of vegetation on channel morphodynamics: Results and insights from laboratory experiments. Earth Surface Processes and Landforms, 35(9), 1014-1028. https://doi.org/10.1002/esp.1908

Thomas, R. E., Johnson, M. F., Frostick, L. E., Parsons, D. R., Bouma, T. J., Dijkstra, J. T., et al. (2014). Physical modelling of water, fauna and flora: Knowledge gaps, avenues for future research and infrastructural needs. Journal of Hydraulic Research, 52(3), 311-325. https:// doi.org/10.1080/00221686.2013.876453

Västilä, K., \& Järvelä, J. (2014). Modeling the flow resistance of woody vegetation using physically based properties of the foliage and stem. Water Resources Research, 50(1), 229-245. https://doi.org/10.1002/2013WR013819

Vettori, D., \& Marjoribanks, T. I. (2021). Temporal variability and within-plant heterogeneity in blade biomechanics regulate flow-seagrass interactions of Zostera marina. Water Resources Research, 57(3), e2020WR027747. https://doi.org/10.1029/2020WR027747

Vettori, D., \& Nikora, V. (2020). Hydrodynamic performance of vegetation surrogates in hydraulic studies: A comparative analysis of seaweed blades and their physical models. Journal of Hydraulic Research, 58(2), 248-261. https://doi.org/10.1080/00221686.2018.1562999

Vettori, D., \& Rice, S. P. (2020). Implications of environmental conditions for health status and biomechanics of freshwater macrophytes in hydraulic laboratories. Journal of Ecohydraulics, 5(1), 71-83. https://doi.org/10.1080/24705357.2019.1669496

Wahid, A., Gelani, S., Ashraf, M., \& Foolad, M. R. (2007). Heat tolerance in plants: An overview. Environmental and Experimental Botany, 61(3), 199-223. https://doi.org/10.1016/j.envexpbot.2007.05.011 
Wu, F.-C., Shen, H. W., \& Chou, Y.-J. (1999). Variation of roughness coefficients for unsubmerged and submerged vegetation. Journal of Hydraulic Engineering, 125(9), 934-942. https://doi.org/10.1061/(asce)0733-9429(1999)125:9(934)

Yamada, M., Hidaka, T., \& Fukamachi, H. (1996). Heat tolerance in leaves of tropical fruit crops as measured by chlorophyll fluorescence. Scientia Horticulturae, 67(1-2), 39-48. https://doi.org/10.1016/s0304-4238(96)00931-4

Yen, B. C. (2002). Open channel flow resistance. Journal of Hydraulic Engineering, 128(1), 20-39. https://doi.org/10.1061/ (asce)0733-9429(2002)128:1(20) 